\title{
A inclusão da violência na agenda da saúde: trajetória histórica
}

\author{
The inclusion of violence in the health agenda: historical trajectory
}

Maria Cecília de Souza Minayo ${ }^{1}$

\footnotetext{
1 Claves, ENSP, Fiocruz. Av. Brasil 4036, sala 700, Manguinhos. 21040-361 Rio de Janeiro RJ. cecilia@claves.fiocruz.br
}

\begin{abstract}
In this article, I seek to provide a systematic record of the historical trajectory of the inclusion of accidents and violence as a legitimate issue of the health area. It will be shown that the process is not concluded, and that it is going on under the pressure of actors and by force of the circumstances. In the beginning, the issue finds a restricted space in the health agenda through the concepts "accidents, injuries and traumas". Since the second half of the 20th century, the rights of different social subjects are incorporated, ranging from observation and notification of violent acts against children, women, the elderly, to the discussion of social violence in its broadest sense, affecting the health of populations. In Brazil, this doubtlessly slow and intermittent process shows some attempts and a pioneer action of the Ministry of Health, carried out in cooperation with and under pressure of social, academic and professional movements: a diagnosis of morbidity and mortality from all kinds of violence, documenting a national policy towards reduction of accidents and violence on national level.
\end{abstract}

Key words Violence and health, Policies for reduction of violence, Accidents and violence, External causes
Resumo Neste texto, busco sistematizar e registrar a trajetória histórica de legitimação do tema dos acidentes e da violência na área da saúde. Mostro que se trata de um processo inconcluso, que ocorre pela pressão de atores e pela força dos acontecimentos. Inicialmente o tema se inclui de forma reduzida, por meio dos conceitos de "acidentes, lesões e traumas". Já a partir da segunda metade do século 20, há a incorporação da pauta de direitos de vários sujeitos sociais, que vai desde a entrada da observação e notificação da violência contra crianças, mulheres e idosos, até a discussão da violência social, no seu sentido mais amplo, afetando a saúde das populações. No Brasil, esse processo, sem dúvida lento e intermitente, tem alguns logros e pioneirismos encenados pelo Ministério da Saúde, com a colaboração e a pressão de movimentos sociais, acadêmicos e profissionais: um documento de diagnóstico da situação de morbimortalidade por todos os tipos de violência; documento de uma Política Nacional de Redução de Acidentes e Violências e um Plano de Ação Nacional. Palavras-chave Violência e saúde, Política de redução da violência, Acidentes e violência, Causas externas 


\section{Introdução}

Neste artigo, buscarei apresentar o percurso de legitimação do tema "violências e acidentes" no âmbito do pensamento e das práticas do setor saúde. Violência e acidentes, ao lado de enfermidades crônicas e degenerativas, configuram, na atualidade, um novo perfil do quadro dos problemas de saúde do Brasil e do mundo. Nesse novo perfil, ressaltase o peso do estilo de vida, das condições sociais e ambientais e da maior longevidade na qualidade de vida, exigindo novas abordagens com as quais o sistema de saúde geralmente não está acostumado. Desde as décadas de 60 e 70 do século passado, houve um grande esforço teórico-metodológico e político para se compreender a saúde como uma questão ampliada, sobretudo, por causa da complexa transição epidemiológica ${ }^{1,2}$. No entanto, nunca um tema provocou e continua a provocar tantas resistências em relação a sua inclusão na pauta do setor como o da violência e acidentes.

Tratarei de dois aspectos: 1) a dinâmica social e setorial de inclusão e paulatina legitimação do tema no âmbito internacional e nacional do campo da saúde; 2) e uma descrição analítica de documentos, planos de ação e iniciativas brasileiras, que demonstram a trajetória sinuosa, lenta, mas persistente de legitimação do problema no interior do pensamento e das práticas de saúde, oferecendo parâmetros, diretrizes e exemplos de possibilidades.

\section{Dinâmica de inclusão do tema "violências e acidentes" na pauta do setor saúde}

É bem verdade que em sua origem e suas manifestações, a violência é um fenômeno sócio-histórico e acompanha toda a experiência da humanidade. Portanto, ela não é, em si, uma questão de saúde pública. Transforma-se em problema para a área porque afeta a saúde individual e coletiva e exige, para sua prevenção e enfrentamento, formulação de políticas específicas e organização de práticas e de serviços peculiares ao setor.

Existem inegáveis evidências da importância dessa problemática para a área da saúde. A Organização Mundial da Saúde (OMS), que, em 1993, escolheu a prevenção de traumas e acidentes como mote da celebração do Dia Mundial da Saúde, repetia em sua justificativa uma frase atribuída a William Forge, segundo o qual: desde tempos imemoriais, as doenças infecciosas e a violência são as principais causas de mortes prematuras ${ }^{3}$. Atualmente, a OMS revela em seu Relatório mundial sobre violência e saúde que todo ano, mais de um milhão de pessoas perdem a vida e muitas outras sofrem lesões não fatais, por causas violentas 4 . Só no Brasil, na década de 1990, ou seja, no espaço de dez anos, mais de um millhão de pessoas morreram por violência e acidentes. Dessas vítimas, cerca de 400 mil faleceram por homicídios. Tanto no mundo como aqui no País, os óbitos infligidos por outros ou auto-infligidos constituem sério problema social e têm intensas repercussões na saúde pessoal e coletiva. No Brasil, desde o início da década de 1980, acidentes e violência constituem a segunda causa de óbito e, para a larga faixa de 5 a 39 anos, são o principal problema de vitimização que leva à morte 5 .

Os danos, as lesões, os traumas e as mortes causados por acidentes e violência correspondem a altos custos emocionais, sociais e com aparatos de segurança pública. Causam prejuízos econômicos por causa dos dias de ausência do trabalho, pelos danos mentais e emocionais incalculáveis que provocam nas vítimas e em suas famílias e pelos anos de produtividade ou de vida perdidos. As conseqüências da violência que chegam ao sistema de saúde, dentre outros aspectos, evidenciam aumento de gastos com emergência, assistência e reabilitação, muito mais onerosos do que a maioria dos procedimentos médicos convencionais 5 . Cálculos do Banco Interamericano de Desenvolvimento, citados por Briceño-Leon ${ }^{6}$, estimam que $3,3 \%$ do PIB brasileiro são gastos com custos diretos da violência, cifra que sobe para $10,5 \%$ quando se incluem custos indiretos e transferências de recursos. Esse autor, falando da América Latina como um todo, afirma que os danos e as transferências de recursos que aqui se processam por causa da violência atingem 14,2\% do PIB da região e equivalem a 168 milhões de dólares. Para se ter idéia do significado da cifra estimada para os custos diretos da violência no País (3,3\% do PIB), ela é três vezes mais elevada do que o valor investido no Brasil, atualmente, em Ciência e Tecnologia.

Apesar de todas as razões citadas, a inclusão da violência na pauta do setor saúde vem ocorrendo muito lentamente. A primeira forma de introdução do tema, à qual se refere William Forge ${ }^{3}$, citado acima, vem se dando, secularmente, dentro da própria lógica biomédica no atendimento pontual e específico das lesões, traumas e mortes. Essas categorias são tradicionalmente contempladas na Classificação Internacional das Doenças (CID) com a denominação "causas externas". O conceito de mortalidade por causas externas sempre incluiu os homicídios, os suicídios e os acidentes; e o de morbidade, as lesões, os envenenamentos, os ferimentos, as fraturas, as queimaduras e intoxicações por agressões interpessoais e coletivas. 
A sensibilização em relação à relevância do tema como pauta para ação de saúde se inicia pioneiramente com a questão da violência contra crianças. Embora existam alguns documentos históricos que mostrem, desde a Antiguidade, uma preocupação da sociedade em regular a subministração de castigos e maus tratos na infância, os primeiros textos que vinculam este tipo de violência com a saúde procedem dos levantamentos de Tardieu, em 18807. Nos anos 60 do século passado, por meio de textos e debates, os profissionais de saúde começaram a fazer denúncias sistemáticas sobre as várias modalidades de violência contra crianças e adolescentes, e sua influência negativa para o crescimento e o desenvolvimento das vítimas ${ }^{8}$. Uma década depois de os pediatras Kempe et al. ${ }^{8}$ cunharem a expressão "síndrome do bebê espancado", vários profissionais, em grande parte dos países, passaram a reconhecer e a diagnosticar este tipo de agravo como um problema de saúde. Programas de prevenção primária e secundária e intervenções, principalmente nas dinâmicas familiares responsáveis pela maioria das agressões, negligências e abusos psicológicos, instituíramse na pauta de serviços de instituições públicas, privadas e ONGs.

Diferentemente da militância que brotou da corporação médica na última metade do século 20, denunciando os abusos que vitimam crianças e adolescentes e buscando solução para o problema, a introdução da violência contra a mulher na agenda da área da saúde ocorreu pelo protagonismo do movimento feminista. Com uma estratégia voltada para criar consciência de gênero nos mais diferentes ambientes e instituições, esse movimento pressionou e pressiona o setor saúde para que atue ativamente e dê respostas concretas, não apenas para o tratamento das lesões e traumas provenientes da violência, mas também para agir nas causas, por meio de uma pauta positiva de ações. Foram endereçadas à área de saúde as mais diferentes problemáticas que afetam a vida e a integridade das mulheres, como agressões conjugais, mutilações, abusos sexuais, físicos e psicológicos, homicídios e uma série de sintomas físicos e psicossomáticos associados à violência de gênero. A força do feminismo na abordagem do diagnóstico situacional e nas propostas de ação relativas a gênero aparece claramente nos documentos dos organismos internacionais do setor saúde, como o que apresenta as conclusões da Conferência sobre Violência e Saúde, realizada pela Organização Pan-americana da Saúde (Opas) em Washington, em 19949,10.
Os maus-tratos contra idosos foram pela primeira vez nomeados em um periódico inglês, em 1975, por meio da categoria "espancamento de avós"11,12, e o tema lentamente foi aparecendo na bibliografia internacional, nacional e nas práticas de proteção, prevenção e atenção. Na área de saúde, os estudos e ações são ainda muito tímidos, mesmo na literatura de países onde tradicionalmente existe forte tradição de pesquisa ${ }^{13}$.

Em toda a sociedade ocidental, e mais particularmente no Brasil, é na década de 1980 que o tema da violência entra com mais vigor na agenda de debates políticos e sociais e no campo programático da saúde. Oficialmente, somente a partir da década de 1990, a Opas e a Organização Mundial da Saúde começaram a falar especificamente do tema "violência" (e não apenas "causas externas"), congregando as várias discussões (sempre dispersas e com pouca legitimidade institucional, até então) que vinham ocorrendo nos diferentes âmbitos e em alguns países.

Em 1994 a Opas convocou os ministros de Saúde das Américas, pesquisadores e especialistas para uma conferência sobre o tema ${ }^{9}$. Nos documentos preparatórios e no documento final desse evento, estão incluídos os aspectos tradicionais que sempre marcaram a atuação do setor e várias outras problemáticas que, pela primeira vez, foram incluídas na pauta, de forma orgânica. Os participantes da conferência entenderam que a transição epidemiológica dos países da região apresentava uma questão antiga com novas cores e evidências, e era preciso defini-la na sua especificidade histórica e mapeá-la, para que fosse tratada com as distinções próprias do setor e nos aspectos da intersetorialidade: A violência, pelo número de vítimase pela magnitude de seqüelas orgânicas e emocionais que produz, adquiriu um caráter endêmico e se converteu num problema de saúde pública em muitos países [...]. O setor saúde constitui a encruzilhada para onde convergem todos os corolários da violência, pela pressão que exercem suas vitimas sobre os serviços de urgência, atenção especializada, reabilitação física, psicológica e assistência social. ${ }^{9}$

Em 2002, a OMS produziu um Relatório mundi$a l^{4}$ em que o termo "causas externas", tradicionalmente usado para categorizar o tema na Classificação Internacional das Doenças e Agravos (CID), foi substituído pela expressão "Violência e Saúde". Em 1997, a OMS já havia realizado uma Assembléia Mundial com ministros de Saúde de todos os países-membros da ONU, em que esse assunto fez parte da pauta. E, em suas recomendações para a região das Américas, a redução da violência já entrara como uma das cinco prioridades ${ }^{14}$. No 
documento de 2002, porém, não resta nenhuma dúvida de que o tema passa a fazer parte do campo de preocupação das organizações internacionais de saúde, merecendo definições, categorizações, problematizações e encaminhamentos. Análises minuciosas (embora de caráter aglomerado) foram apresentadas, e no relatório há uma série de recomendações para todo o setor. Uma delas é de que cada país faça seu próprio diagnóstico e plano de ação.

Atendendo a esse chamado, em 2005, o Ministério da Saúde, junto com a representação brasileira da Opas e do Claves/Fiocruz, produziu e divulgou um relatório, seguindo mais ou menos a linha do texto internacional, denominado Impacto da violência na saúde dos brasileiros ${ }^{15}$. Além disto, também está sendo implantado um plano de ação como se verá à continuação.

Trajetória de inclusão da violência na agenda do setor saúde do Brasil

No Brasil, a inclusão da violência e da criminalidade na agenda da cidadania coincide com o término (oficial) da ditadura militar. Os movimentos sociais pela democratização, as instituições de direito e a forte pressão de algumas entidades não-governamentais e organizações internacionais, com poder de influenciar o debate nacional, foram fundamentais para tornar a violência social uma questão pública.

Na área de saúde, no País, a consideração do tema da violência vem se fazendo de forma fragmentada e progressiva. Primeiramente, pediatras epidemiologistas e psiquiatras trouxeram o problema ao debate, embora enfermeiras, assistentes sociais e demais profissionais do campo da assistência tivessem consciência dele. Os primeiros, seguindo as trilhas de Kempe et al. ${ }^{8}$, como já demonstrado ${ }^{16}$; os segundos, produzindo importantes estudos de magnitude e evidenciando tendências ${ }^{16}$; os últimos, analisando as relações das agressões com enfermidades mentais, com ênfase em estudos sobre suicídio ${ }^{16}$. Seus trabalhos se iniciam nos anos 70 do século 20, mas o incremento maior da contribuição científica da área sobre o tema ocorre a partir dos anos 80 . Seu aporte na produção científica e na prática da atenção, nos últimos 25 anos, é de mais $90 \%$ em relação a qualquer período histórico anterior ${ }^{16}$.

Do ponto de vista da atuação, alguns pediatras iniciaram atividades assistenciais e de prevenção nos hospitais onde trabalhavam e construíram algumas ONGs, com o propósito de tratar de temáticas peculiares, dentro de propostas que incluíam e também ultrapassavam os marcos tradicionais do setor saúde. Assinalo o pioneirismo das atividades dos Crami (Centros Regionais de Atenção aos Maus Tratos na Infância), em São Paulo; da Abrapia (Associação Brasileira Multiprofissional de Proteção à Infância e à Adolescência), no Rio de Janeiro; e da ABNAPI (Associação Brasileira de Prevenção aos Abusos e Negligências na Infância), em Minas Gerais $^{14}$, como exemplos de entidades surgidas nos anos 80, com intervenções abrangentes, que pensavam, atuavam e produziam, especificamente, dando assessoria a políticas públicas no tema da violência na infância e na adolescência.

No âmbito da proteção à infância, profissionais comprometidos com a saúde e com o desenvolvimento integral de crianças e adolescentes participaram ativamente de um forte movimento em prol da cidadania deste grupo, que redundou na criação do Estatuto da Criança e da Adolescência (ECA), promulgado em 1990. Hoje existe um número bastante significativo de programas e iniciativas da sociedade e do Estado que focalizam o problema em pauta, e neste número da revista Ciência \& Saúde Coletiva, há artigos que revelam exemplos exitosos de atuação. Um documento importantíssimo da Secretaria de Estado dos Direitos Humanos do Ministério da Justiça com caráter intersetorial e, portanto, contando com a contribuição do Ministério da Saúde e de profissionais da área, é o Plano Nacional de Enfrentamento da Violência Sexual Infanto-Juvenil de 200217. Neste plano, não só foi feito um diagnóstico da situação, como se criaram condições para defesa de direitos das crianças e adolescentes vítimas, atribuídos aos responsáveis, de normas de atendimento e de prevenção. Construíram-se, também, indicadores para monitoramento e comprovação da efetividade da ação nacional.

A participação do movimento de mulheres brasileiras na introdução da violência como tema de saúde no Brasil teve expressão fundamental na construção do Programa de Atenção Integral à Saúde da Mulher (PAISM) ${ }^{18}$, promulgado em 1983. Esse programa incorpora de forma clara a pauta dos direitos sexuais e reprodutivos, que dá lugar de destaque à reflexão sobre a violência de gênero. O Programa de Assistência Integral à Mulher ${ }^{18}$ leva em conta a relevância do tema da violência e oficializa um tipo de olhar específico para o problema em todo o serviço público. É importante acrescentar que o lançamento, em 2004, da Política Nacional de Direitos Sexuais e de Direitos Reprodutivos ${ }^{19}$ e um plano de ação que contempla o período de 2004 a 2007 aprofunda as proposições do PAISM. De acordo com os princípios e diretrizes dessa política e do plano de 
ação, o Ministério da Saúde estabeleceu como meta aumentar em 30\% os serviços de atenção às mulheres e às adolescentes em situação de violência nos municípios-pólos de microrregiões, apoiando-se na organização de redes integradas, nesse período de quatro anos.

A promulgação do Estatuto do Idoso pela Secretaria Especial de Direitos Humanos, em 200320, trouxe o tema da violência como pauta intersetorial, incluindo a área de saúde. Em 2005, foi oficializado um plano de ação intersetorial ${ }^{21}$ de enfrentamento da violência contra a pessoa idosa. Ao setor saúde, cabem ações de promoção, prevenção de agravos, atendimento às várias formas de violência e normalização das casas e clínicas de longa permanência.

Já na metade dos anos 90, muitas secretarias de saúde municipais, em articulação com organizações da sociedade civil, criaram estratégias e serviços de prevenção e de assistência às resultantes da violência. Tais iniciativas se multiplicaram desde então, geralmente congregando instituições públicas, ONGs e institutos ou grupos de pesquisa. Destaque precisa ser dado à Faculdade de Saúde Pública da USP ${ }^{13}$, que tem uma linha de investigação sobre "causas externas" desde a década de 70 do século passado, e à Fundação Oswaldo Cruz que, em 1989, criou, na Escola Nacional de Saúde Pública (ENSP), o Centro Latino-Americano de Estudos sobre Violência e Saúde (Claves), com a função de produzir pesquisas estratégicas e interdisciplinares, formar profissionais e assessorar as políticas públicas do setor ${ }^{14}$. Atualmente, o Claves está associado ao Instituto Fernandes Figueira, dentro dos mesmos objetivos, com o Centro de Informação, Comunicação em Saúde e com a Bireme (OPAS), para a construção e alimentação de um núcleo de documentação e divulgação científica e de uma biblioteca virtual. É também centro colaborador da Secretaria de Vigilância em Saúde do Ministério da Saúde.

Em 1998, o Conselho Nacional dos Secretários Municipais de Saúde (Conasems), com a assessoria do Claves, instituiu um plano de ação de prevenção da violência contra crianças e adolescentes, em parceria com a Unicef e a Unesco, incluindo orientações gerais para o conjunto dos municípios $^{22}$. Nos últimos quatro anos, essa organização passou a fazer parte da Rede Gandhi como âncora desta instituição, e, a partir de então, o tema da não-violência e da cultura da paz foi incluído na pauta de ação de vários municípios e de todos os congressos desse conselho, que reúne os mais de 5.500 secretários de saúde do País.

Ainda em 1998, o Ministério da Saúde insti- tuiu um grupo de trabalho para assessorá-lo na formulação de uma Política Nacional de Redução de Acidentes e Violências. Em maio de 2001, foi promulgada uma portaria do Ministério da Saúde oficializando o documento de definição da políti$\mathrm{ca}^{23}$, com desdobramentos em todas as áreas de atenção à saúde, informação em saúde, bem como nas linhas de prevenção. E, recentemente, em 2005, foi também promulgado um plano de ação setorial. Desses dois últimos dispositivos falarei mais detalhadamente. Essa e as outras iniciativas dos órgãos públicos nasceram da pressão ou articulação de movimentos sociais e internacionais e de intelectuais que passaram não só a evidenciar a magnitude do problema como a propor estratégias, em diferentes níveis, para reduzir ou superar a violência.

O documento da Política Nacional de Redução de Acidentes e Violência ${ }^{23}$, aprovado por portaria do Ministro da Saúde em maio de 2001, trata, em primeiro lugar, o tema em pauta como um problema social e histórico e o situa nos marcos da promoção da saúde e da qualidade de vida. É no mesmo sentido que define os conceitos de "violência" e a distingue de "acidentes", (uma vez que, tradicionalmente, esses dois termos vêm juntos na CID sobre causas externas). A seguir, faz um diagnóstico geral do problema, das formas como ele afeta o setor saúde, e como este próprio setor, por ser parte da sociedade em que a violência está configurada, também a gera e a reproduz. Analisa as fontes de informação e documentação oficiais existentes, sua importância e suas deficiências. O diagnóstico situacional, embora referencie dados aglomerados que dizem respeito ao País como um todo, apresenta detalhadamente as várias formas de manifestação do problema (agressão física, abuso sexual, violência psicológica, omissões, violência interpessoal, institucional, social, no trabalho, política, estrutural, cultural, criminal e de resistência). Também distingue as formas como a violência incide em homens e mulheres e nas diversas faixas etárias. Analisando-se esse texto oficial, observa-se um processo crescente de tomada de consciência sobre o problema, deixando aberturas para novas inserções. Quando foi escrito, por exemplo, eram quase inexistentes os programas ministeriais que levavam em conta violência e discriminações por raça/etnia/cor e opção sexual (a não ser no tema específico da Aids), assim como para com a população portadora de necessidades especiais. Desta forma, a política nacional não trata esses assuntos, o que hoje é considerável uma imperdoável omissão, caso tais atores e questões não estejam integrados em diretrizes de ação. 
O documento de políticas descreve e analisa também as várias leis, portarias, normas e dispositivos setoriais e intersetoriais que fazem interface e interagem com as informações do setor saúde e sua prática, como é o caso, em termos de legislação, do Código Nacional do Trânsito promulgado em 1997. Quanto aos dispositivos, o documento trata da declaração de óbitos, dos boletins de ocorrência policial, dos boletins de registro de acidentes de trânsito; da certidão de acidente de trabalho (CAT). E sobre os dados existentes, refere-se aos sistemas de informação do SUS para mortalidade (SIM), morbidade (SIH/SUS) e envenenamentos e intoxicações (Sinitox). O texto apresenta, como constatação, que inexiste um dispositivo nacional que sistematize e analise os acidentes de trânsito. O mesmo ocorre com as informações da área de segurança pública. As CATs, por sua vez, são insuficientes, pois apenas informam os dados dos acidentes e violência no trabalho para os que possuem carteira assinada.

Os princípios que fundamentam o documento de políticas são os mesmos que orientam o SUS: 1) saúde como direito fundamental e como requisito para desenvolvimento social e econômico; 2) direito ao respeito à vida como valor ético; promoção da saúde como fundamento de qualquer ação para redução da violência e acidentes. Esses princípios baseiam as diretrizes a serem seguidas nos planos nacionais, estaduais e municipais.

As diretrizes, condizentes com os princípios, assim se resumem: 1) promoção da adoção de comportamentos e ambientes seguros e saudáveis; 2) monitoramento da ocorrência de acidentes e violência; 3) sistematização, ampliação e consolidação do atendimento pré-hospitalar; 4) incremento de uma forma de assistência multiprofissional às vítimas de violência e acidentes; 5) estruturação e consolidação dos serviços de recuperação e reabilitação; 6) investimento na capacitação de recursos humanos, em estudos e em pesquisas específicas, sobretudo nos assuntos que possam iluminar as práticas nos três níveis, principalmente, o local.

O texto da política também distribui responsabilidades institucionais, tendo como critério a articulação intersetorial nos âmbitos dos governos federal, estaduais e municipais e com a sociedade civil, nas áreas de desenvolvimento urbano, justiça e segurança, trabalho, emprego e previdência social, transportes e ciência e tecnologia. Cita, especificamente, o papel das universidades, defendendo que elas não podem ficar alheias a este problema que hoje afeta profundamente a sociedade brasileira. Propõe-lhes, nesse sentido, que promovam formação de recursos humanos para lidar com os proble- mas específicos de violência e atuem em pesquisas de caráter estratégico, para que haja impacto positivo sobre o problema tratado, a partir de diagnósticos cientificamente informados.

Por fim, o documento em discussão dedica um capítulo ao tema do acompanhamento e da avaliação como forma de atuar na implantação e na implementação monitorada da política pública, sobretudo pelo fato de a violência ser um tema relativamente novo no setor saúde. Esse monitoramento necessita ser encarado de forma muito diferente daquela que a área tem tradição, nos processos de vigilância epidemiológica convencional. Sabiamente, o texto fala da necessidade de desenvolvimento de parâmetros, critérios e metodologias específicas; acompanhamento das experiências e avaliação periódica.

É preciso ressaltar que o texto que apresenta a política foi escrito por uma equipe de especialistas de várias áreas (seguindo o critério de que a violência é um problema complexo, e qualquer atuação precisa ser desempenhada de forma intersetorial), junto com técnicos do Ministério da Saúde. Antes de ser promulgado, seu conteúdo passou por um abrangente seminário nacional com estudiosos, profissionais que atuam nos vários tipos e níveis de atendimento na área de saúde e membros da sociedade civil. Por isso, configura uma produção coletiva. Depois desse processo, o documento foi encaminhado à Comissão Tripartite e aprovado por esta instância do SUS, que reúne os mais importantes representantes do Ministério da Saúde, os presidentes do Conselho Nacional dos Secretários Estaduais de Saúde (Conass) e do Conasems. Em abril de 2001, o Conselho Nacional de Saúde confirmou o parecer da Tripartite, e, em maio, o texto foi aprovado oficialmente por meio da Portaria MS/GM no. 737, de 16/5/01, publicada no Diário Oficial no 96, seção 1e, de 18/5/0123.

Desde que a portaria do Ministério da Saúde foi promulgada, a partir do nível central do SUS, foi organizada a Área Técnica para Acidentes e Violências. Seu objetivo foi mobilizar, articular e pactuar ações integradas intra e intersetoriais, orientando parcerias técnicas, institucionais e financeiras para a estruturação de uma rede nacional de enfrentamento dessa questão. Foi construído um Programa de Redução de Morbimortalidade por Acidentes de Trânsito, com recursos do DPVAT (seguro de danos pessoais causados por veículos automotores de vias terrestres). Foram incentivadas várias ações locais em estados e municípios, dentre elas, a implantação de um programa específico para coleta de dados, contemplando variáveis que não vinham sendo levadas em conta nos sis- 
temas tradicionais. Também foram realizados, em 2002, quatro seminários macro-regionais sobre violência urbana e saúde pública, em uma parceria entre Ministério da Saúde, Conselho Nacional de Saúde e Congresso Nacional.

Um dos passos mais importantes, no entanto, foi a formulação do Plano de Ação, que teve sua construção iniciada em 2003 e sua implantação e implementação, em 200524. O processo de sua construção envolveu muitos atores governamentais e não governamentais. Esse plano foi formalizado pela portaria 936 do Ministério da Saúde, de 18/05/2004, que dispõe sobre a estruturação da Rede Nacional de Prevenção da Violência e Promoção da Saúde e a implantação e implementação de Núcleos de Prevenção à Violência em estados e municípios. Para a formulação desse instrumento, inicialmente, foi feito um diagnóstico, por meio do qual, aliado a um indicador composto, o Ministério da Saúde estabeleceu um ranking dos municípios com mais de 100 mil habitantes, onde a situação de violência (configurada por taxas de mortalidade por homicídios, acidentes de trânsito e suicídio) fosse mais dramática.

Por contar com parcos recursos orçamentários para a execução do plano, a Secretaria de Vigilância em Saúde do Ministério da Saúde, onde o programa de redução de acidentes e violências está alocado, contemplou: 1) os 40 primeiros da lista; 2) os municípios onde vinham sendo desenvolvidas ações do Programa de Ação Integrada de Enfrentamento da Violência Sexual Infanto-juvenil no Território Nacional (Pair), 3) os municípios de fronteira, onde se realizavam ações integrais de prevenção da violência e promoção da saúde, e 4) estados com mais de um município selecionado pelos critérios acima. Todos contam com fundos para a criação de núcleos de atuação, de formação de recursos humanos e de desenvolvimento de pesquisas, tendo seu funcionamento orientado por diretrizes do Ministério da Saúde.

Durante o ano de 2005 se deu a configuração dessas iniciativas, que vêm sendo implementadas em 2006. Criaram-se também, como parte do plano, núcleos em 15 universidades das distintas regiões do País, com missões diversas, de acordo com suas competências e com uma encomenda específica do Ministério da Saúde para cada uma: criação de redes, apoio na formação de recursos humanos, desenvolvimento de pesquisas, monitoramento da implantação dos núcleos de atuação e avaliação das ações de redução. Essa iniciativa está, pois, em processo de implantação e implementação, e, certamente, serão necessários pelo menos de dois a três anos para que as atividades apresentem resultados.
É preciso assinalar também, como relevante, um edital específico da Secretaria de Ciência e Tecnologia do Ministério da Saúde em 2004 que, levando em conta as orientações do documento de políticas, passou a investir em pesquisas estratégias sobre a problemática. Precedido de um seminário que reuniu especialistas de todo o País, visando a estabelecer prioridades, os temas propostos para investigação corresponderam às amplas necessidades de conhecimento nacional e locais, sendo que os resultados dessa inflexão sobre o tema ocorrerão ao fim de 2006, pois o edital selecionou projetos para serem realizados em dois anos, 2005-2006.

Em resumo, no período de 2001 a 2006, o Ministério da Saúde apresentou importante evolução na legitimação da Política Nacional de Redução da Morbimortalidade por Acidentes e Violências (2001): 1) a Portaria 1.968/200125, que trata da notificação obrigatória pelos profissionais de saúde das situações de suspeita ou confirmação de maus-tratos contra crianças e adolescentes; 2) Portaria 1.969/200126, que dispõe sobre o registro e o preenchimento da Autorização de Internação Hospitalar (AIH) nos casos de atendimento das causas externas; 3 ) as Portarias SAS/MS n ${ }^{\circ} 96927$ e $970 / 2002^{28}$, que disponibilizam uma nova ficha de registro de entrada de pacientes no SUS, com a intenção de captar com mais qualidade aqueles advindos dos acidentes e violência. São passos importantes, embora não suficientes, pois podem redundar apenas em maior burocratização do problema, em lugar de torná-lo uma questão de debate público.

Outros avanços podem ser observados a partir do ano 2001 na área de Saúde Mental, que passou a discutir a inserção do atendimento a mulheres, crianças e adolescentes em situação de violência nos Centros de Apoio Psicossocial (Caps); no campo da Saúde do Adolescente e do Jovem, apoiando atividades de protagonismo juvenil como prevenção da violência; na área de Saúde do Idoso e do Portador de Deficiência, que recém-começa a inserir a temática da violência em suas linhas de atuação. Em 2005, o Ministério da Saúde lançou várias normas técnicas como as que tratam sobre atendimento aos agravos decorrentes da violência sexual ${ }^{29}$; sobre a anticoncepção de emergência nos casos de violência sexual contra mulheres e adolescentes ${ }^{30}$ e sobre a atenção humanizada às situações da interrupção da gravidez prevista em lei ${ }^{31}$. Em 2004, a Portaria GM/MS 2.406 disseminou a notificação compulsória da violência contra a mulher, de acordo com as leis 10.778/200332, que estabelece essa forma de registro, e 10.886/2004 33 . Mais recen- 
temente, em 2006, lançou a "matriz pedagógica" para formação de Redes de Atenção Integral para Mulheres e Adolescentes em situação de violência doméstica e sexual ${ }^{34}$.

É relevante dizer que existe um grande número de experiências de prevenção da violência ocorrendo em todo o País. Artigos desta revista tocam em algumas propostas que podem considerar-se exitosas. Todas são intersetoriais, articulam ações do estado e da sociedade civil e contam com o apoio das universidades. Algumas intervenções, em que a questão da cidadania e o cuidado com os jovens são os focos, já mostram impacto na diminuição das taxas de homicídio em nível local, como é o caso das experiências ocorridas em Diadema, São Paulo, e em Belo Horizonte. No âmbito dos acidentes de trânsito, que matam quase 30 mil brasileiros por ano, as atividades com múltiplos focos e parceiros também evidenciam resultados positivos em municípios onde as taxas de óbito são altas, como é o caso de Recife, Curitiba, São Paulo, Belo Horizonte e Goiânia $^{35}$.

Por fim, está em andamento a preparação de um curso a distância (EAD da ENSP/Claves/Fiocruz, em convênio com o Ministério da Saúde) que se iniciará em 2006, visando à formação, inicialmente, de 500 gestores e profissionais, para que elevem a qualidade das informações sobre violência e acidentes, sejam capazes de produzir diagnósticos locais e promovam ações de prevenção nos marcos da promoção da saúde. Com certeza, essa iniciativa significará um passo importante na socialização e na internalização do tema pelo setor.

\section{Conclusões}

Minha intenção ao apresentar essa trajetória do tema "violências e acidentes" na área de saúde foi, de um lado, mostrar as dificuldades de sua legitimação, sobretudo nas instâncias que dão diretrizes para a atuação do setor. A maioria dos entraves decorre das dificuldades que o setor, profundamente marcado pela racionalidade biomédica, tem de aceitar, em seu modelo e dinâmica, problemas complexos cuja tônica são questões da vida social e não doenças. Freqüentemente ocorre-me perguntar se: morrem mais vítimas de Aids ou câncer do que de acidentes de trânsito ou homicídio?. Nesta pergunta não vai uma valorização da quantidade - pois o número de pessoas que vão a óbito por essas doenças é muito menor do que os vitimados por violência. Não está em jogo uma oposição entre os que passam por grande sofrimento com enfermidades degenerativas ou incapacitantes e os que sofrem violência, mas o seguinte princípio ético: se todos morrem e todas as vidas são preciosas, o investimento nas várias áreas é importante e crucial. Continuam sendo muito escassos os recursos (financeiros, de gestão, humanos e culturais) investidos na construção da complexa problemática e na busca de soluções adequadas que devem ser desenvolvidas dentro do setor ou em colaboração com outros âmbitos, como é o caso da segurança pública.

Por outro lado, quis também valorizar o caminho já percorrido. A experiência mostra que, quando há ganhos e resultados positivos provenientes dos difíceis passos dados, as pessoas se dispõem a continuar com mais ânimo e coragem. Por isso, empenhei-me em evidenciar os caminhos lentos e tortuosos pelos quais vai passando a inclusão do tema na pauta do setor. Há pelo menos três fatos que se constituem em símbolo dos resultados que vão sendo alcançados ao longo do processo. $\mathrm{O}$ primeiro é a construção coletiva e a promulgação do Documento da Política Nacional de Redução dos Acidentes e Violências, pois, ao que parece, o País é pioneiro em adotá-lo. O segundo é a elaboração de um plano nacional para aplicação da política, fundamentado em estudos e bases epidemiológicas. Igualmente, parece que o Brasil saiu na frente nessa ação planejada. E, em terceiro lugar, o documento denominado Impacto da violência sobre a saúde dos brasileiros atende a uma recomendação da OMS de que cada país promova o seu diagnóstico para fundamentar suas ações. A iniciativa brasileira é também pioneira. Oxalá todos os esforços empreendidos para criar parâmetros e diretrizes, frutos de tantas vozes simultâneas clamando por qualidade de vida e sob o influxo de tantas mortes evitáveis, sejam acompanhados de ações setoriais e intersetoriais condizentes e necessárias. O setor saúde, além da tradição de prevenção, tem a ótica do cuidado como ethos, no que se diferencia da práxis da segurança pública, que visa a reprimir crimes e contravenções. Essa tradição do cuidado e da prevenção pode fazer toda a diferença! 


\section{Referências}

1. Barreto ML, Carmo H. Mudanças em padrões de morbimortalidade: conceitos e métodos. In: Monteiro CA. Velhos e novos males da saúde no Brasil. São Paulo: Hucitec/Nupens; 1995. p. 7-32.

2. Omram AR. The epidemiologic transition. The Milbank Mem. Fund. Q. 1971; 3:509-83.

3. Organização Mundial de Saúde. Salud Mundial. Genebra: OMS; 2003

4. Organização Mundial de Saúde. Relatório mundial sobre violência e saúde. Brasília: OMS/Opas; 2002.

5. Minayo MCS. Violência, um problema para a saúde dos brasileiros: introdução. In: Souza ER, Minayo MCS, organizadores. Impacto da violência na saúde dos brasileiros. Brasília: Editora do Ministério da Saúde; 2005. p. 9-33.

6. Briceño-León R, organizador. Violencia, sociedad y justicia en América Latina. Buenos Aires: Clacso; 2002.

7. Assis SG. Crianças e adolescentes violentados: passado, presente e perspectiva para o futuro. Cad Saúde Pública 1994; 10(Supl 1):126-34.

8. Kempe CH, Silverman FN, Steele BF, Droegemueller W, Silver HK. The battered child syndrome. J Am Med Assoc 1962; 181:17-24

9. Organização Pan-americana de Saúde. Violência y Salud. Resolución no XIX. Washington D.C. : Opas; 1994.

10. Heise L. Violence against women: The hidden health burden. Discussion paper prepared for the World Bank. Washington: World Bank; 1993 [mimeo].

11. Baker AA. Granny Battering. Modern Geriatrics 1975; 5:20-4.

12. Burston GR. Granny Baterring. BMJ 1975, 3:592.

13. Wolf RS. Maltrato em ancianos. In: Anzola Perez E. Atención de los ancianos: um desfio para los noventa.Washington D.C. : Opas; 1995. p. 35-42.

14. Minayo MCS, Souza ER. É possível prevenir a violência? Rev C S Col 1999; 4(1):7-24.

15. Brasil. Ministério da Saúde. Secretaria de Vigilância em Saúde. Impacto da violência na saúde dos brasileiros. Brasília: Ministério da Saúde; 2005.

16. Minayo MCS, organizadora. Bibliografia comentada da produção científica brasileira sobre violência e saúde. Rio de Janeiro: Editora Panorama, Ensp; 1990.

17. Brasil. Ministério da Justiça. Plano Nacional de Enfrenta-mento da Violência Sexual Infanto-Juvenil. Brasília: Ministério da Justiça; 2002

18. Brasil. Ministério da Saúde. Programa de Assistência Integral à Saúde da Mulher. Brasília: Ministério da Saúde; 1983.

19. Brasil. Ministério da Saúde. Política Nacional de Direitos Sexuais e de Direitos Reprodutivos. Brasília: Ministério da Saúde; 2004.

20. Brasil. Ministério da Justiça. Secretaria Especial de Direitos Humanos. Estatuto da Pessoa Idosa. Brasília: Secretaria Especial de Direitos Humanos; 2003.

21. Brasil. Ministério da Justiça. Secretaria Especial de Direitos Humanos. Plano de Ação de Enfretamento da Violência Contra a Pessoa Idosa. Brasília: Secretaria Especial de Direitos Humanos; 2005.
22. Conselho Nacional dos Secretários Municipais de Saúde. Plano de Ação de Redução da Violência contra Crianças e Adolescentes. Brasília: Conasems; 1988.

23. Brasil. Ministério da Saúde. Política Nacional de Redução da Morbimortalidade por Acidentes e Violências. Brasília: MS; 2001.

24. Brasil. Ministério da Saúde. Plano Nacional de Redução de Acidentes e Violências. Brasília: Ministério da Saúde; 2005.

25. Brasil. Ministério da Saúde. Portaria GM/MS n 1.968/2001. Dispõe sobre a obrigatoriedade de notificação de suspeita ou confirmação de maus-tratos cometidos contra crianças e adolescentes aos conselhos tutelares. Brasília: MS; 2001.

26. Brasil. Ministério da Saúde. Portaria GM/MS nº 1.969/2001. Dispõe sobre o preenchimento de campos obrigatórios na autorização de internação hospitalar em casos de causas externas, acidentes e doenças relacionadas ao trabalho. Brasília: MS; 2001

27. Brasil. Ministério da Saúde. Portaria SAS/MS no 969/2002. Dispõe sobre ficha de atendimento ambulatorial de emergência para o SUS. Brasília: MS; 2001.

28. Brasil. Ministério da Saúde. Portaria SAS/MS no 970/2002. Dispõe sobre a aprovação e implantação do Sistema de Informações em Saúde para os Acidentes e Violências (Sisav). Brasília: MS; 2002

29. Brasil. Ministério da Saúde. Norma técnica de prevenção e tratamento dos agravos resultantes da violência sexua contra mulheres e adolescentes. Brasília: MS; 2005.

30. Brasil. Ministério da Saúde. Norma técnica sobre anticoncepção de emergência. Brasília: Ministério da Saúde; 2005.

31. Brasil. Ministério da Saúde. Atenção humanizada ao abortamento: norma técnica. Brasília: MS; 2005.

32. Lei no 10.778 de 24 de novembro de 2003. Estabelece a notificação compulsória, no território nacional, do caso de violência contra a mulher que for atendida em serviços de saúde públicos ou privados. Diário Oficial da União 2003; 25 de nov.

33. Lei $n^{\circ} 10.886$ de 17 de junho de 2004 . Acrescenta parágrafos ao artigo 129 do decreto-lei $n^{\circ} 2.848$, de 07 de dezembro de 1940 - Código Penal, criando o tipo especial denominado "violência doméstica". Diário Oficial da União 2004; 18 de jun.

34. Brasil. Ministério da Saúde. Atenção integral para mulheres e adolescentes em situação de violência doméstica e sexual - Matriz pedagógica para formação de redes. Brasília: MS; 2006.

35. Minayo MCS, Souza ER. Avaliação do processo de implantação e implementação do Programa de Redução da Mor bimortalidade por Acidentes de Trânsito: municípios de Recife, Belo Horizonte, Goiânia, São Paulo e Curitiba [relatório]. Rio de Janeiro: Claves; 2006.

Artigo apresentado em 22/03/2006

Aprovado em 31/03/2006

Versão final apresentada em 31/03/2006 